\title{
NUMERICAL SIMULATION OF INLET FOR TURBINE ASSISTED
}

\section{RAMJET}

\author{
G. Madhan Kumar ${ }^{1}$, S. Sam Vimal Kumar ${ }^{2}$, S. Z. Syed Afsar ${ }^{3}$, R. Selvamani ${ }^{4}$ \\ ${ }^{1}$ Assistant Professor, Department of Aeronautical Engineering, SNS College of Technology, Tamil Nadu, India \\ ${ }^{2,3,4}$ Student, Department of Aeronautical Engineering, SNS College of Technology, Tamil Nadu, India
}

\begin{abstract}
The ramjet engine performs faster than a Turbojet Engine at higher Mach numbers, but the engine can't start with the own power itself. The starting thrust must be attained by additional thrust producing devices like solid rocket boosters. The more reasonable solution to overcome the starting problem is the integration of ramjet engine with turbojet engine, which leads to the Turboramjet. This work describes some challenges in the design of an inlet for turbo-ramjet. Since it is a critical component, its design has important effects on the overall performance of the engine. Here this work deals with a design of a turbo ramjet inlet and an analysis for its optimization. Our aim is to reduce total pressure loss and entropy rise. A design of turbo-ramjet intake is made with CATIA as well as a complete engine for better understanding. Gambit is used to mesh the geometry while ANSYS 14 is used to perform the analysis for design optimization.
\end{abstract}

Key Words: Ramjet, Inlet, Turbine assisted, Subsonic and Supersonic Diffuser. -***

\section{INTRODUCTION}

The Turbo-ramjet engine is a combined cycle engine that merges aspects of turbojet and ramjet engines. The turbojet engine is effective up to Mach 2.2 and afterburner is used to propel the aircraft to Mach 4. After that the Ramjet engine starts producing thrust. The ultimate advantage of turboramjet engine is that it can produce thrust from take-off to hypersonic Mach numbers without the need of auxiliary propulsion device. Since the turbo-ramjet provide housing for two engines i.e. turbojet and dual-mode ramjet, there must be two separate intakes for two engines. The turboramjet intake must operate effectively from subsonic to hypersonic Mach number. The turbo-ramjet must have a variable geometry intake for its effective operation as well as to improve the reliability.

Since the engine operates over a wide Mach number range, the total pressure loss is high. This affects the overall performance of the engine.[1] Optimizing the performance of the inlet is to operate over a range of Mach numbers at the concerned angle of attack.[6] It is to be noted that the flow in hypersonic air-breathing engine is still supersonic at the end of the inlet and before the combustor.[10] The interaction of oblique shock by the inlet ramp in hypersonic flow is observed. This shock may force the boundary layer to separate from the wall, resulting in pressure losses and a reduction of the inlet efficiency.[5]

The design criterion is to maximize total pressure recovery. At a flight Mach number of 2.2, a practical number of $95 \%$ total pressure recovery is desired for a long duration cruise transportation aircraft.[9] Our work carries the pressure recovery of inlet at various Mach Number conditions pertaining the viscous shock interactions.

\section{TURBO-RAMJET INTAKE}

The turbo-ramjet engine is associated with a common intake and nozzle for turbojet and ramjet. The movable cowl separates the flow between the turbojet and ramjet. The turbo-ramjet intake must have the property of subsonic and supersonic intake as shown in Fig. 1

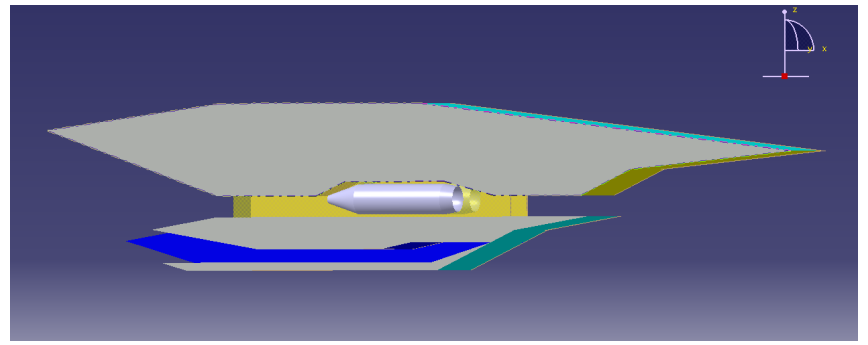

Fig -1: Turbo-Ramjet Engine Design using CATIA

Ramjet Engine operation is dual mode as it is carried with two inlets: one for jet Engine and the other for Ramjet as shown in Fig. 2

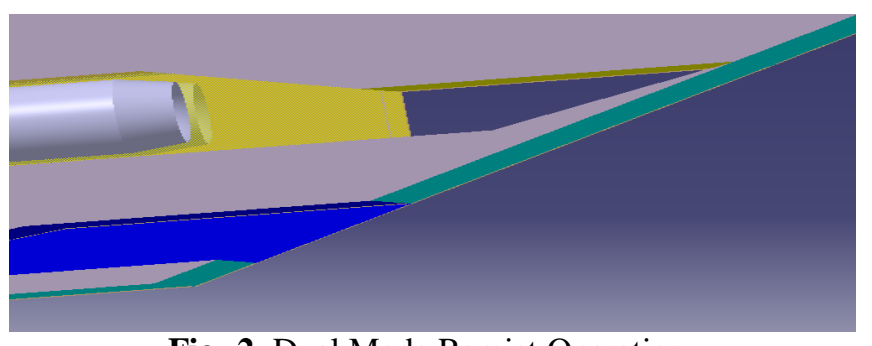

Fig -2: Dual Mode Ramjet Operation

\section{MESHING}

The domain of rectangular shape is created over the model. The triangular mesh is created in almost all the regions 
except in very few areas. The quadrilateral mesh is introduced inside the duct for accurate solutions. The quadrilateral mesh is very fine to show the contour variations more precisely.

\subsection{Turbo Jet Operation}

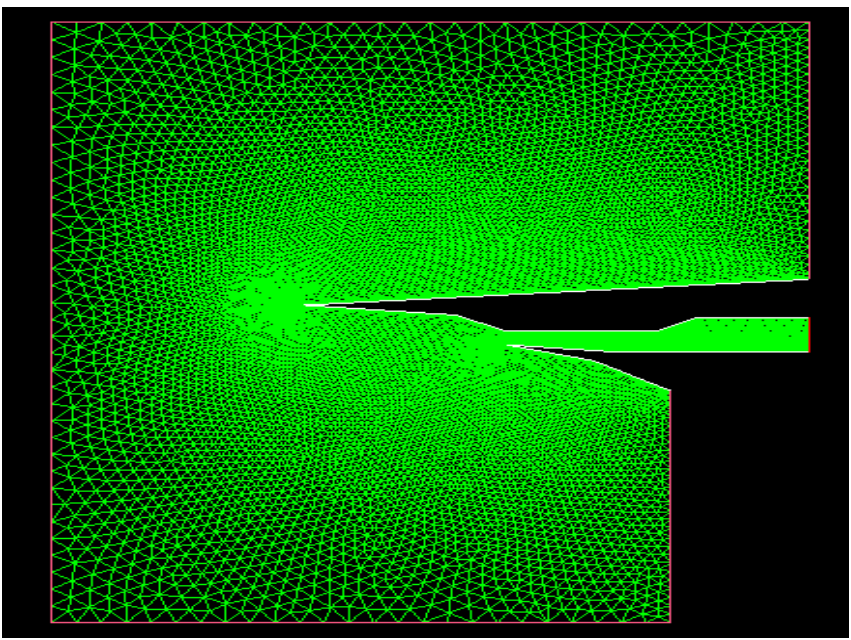

Fig -3: Complete Meshing Domain

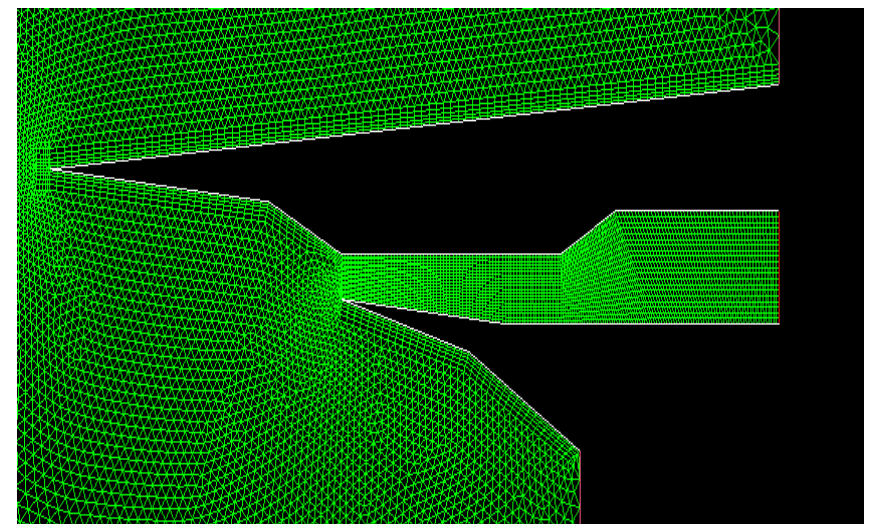

Fig -4: Quadrilateral and triangular mesh variation

\subsection{Dual Mode Operation}

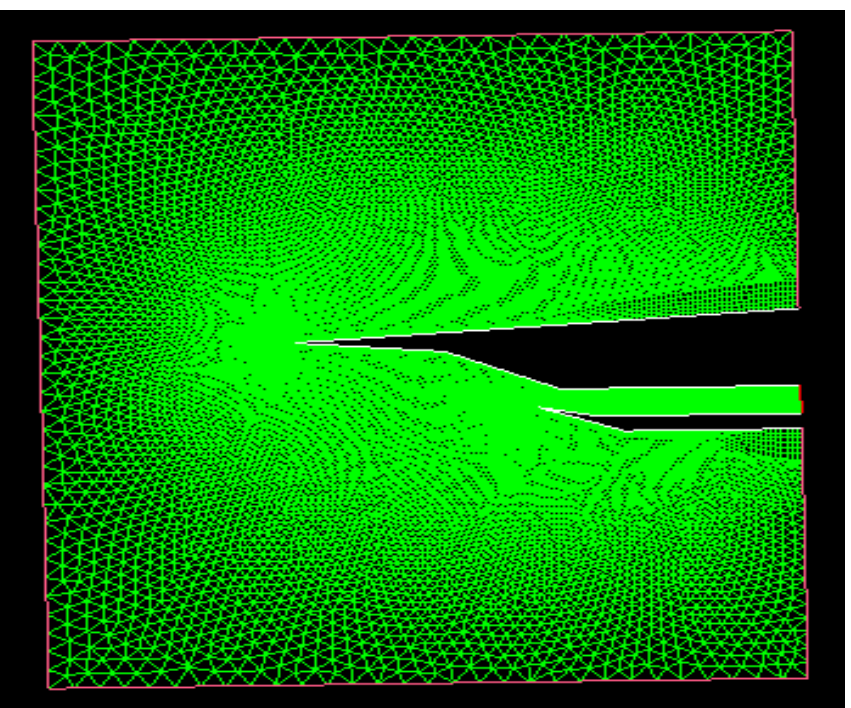

Fig -5: Complete Meshing Domain

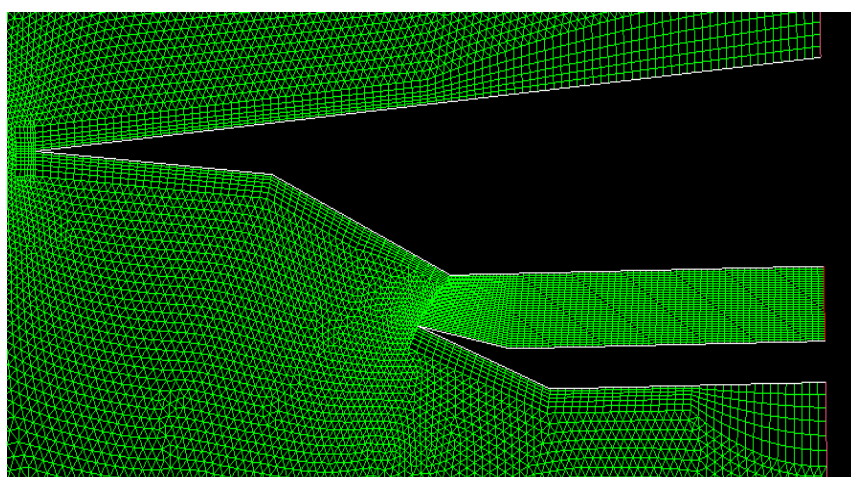

Fig -6: Quadrilateral and triangular mesh variation

\section{BOUNDARY CONDITIONS}

The inlet is first analyzed with the applied Boundary Conditions. The flow was initialized with the air inlet at various Mach numbers at an altitude of $30000 \mathrm{ft}$ and the coupled type of solving was used for the iteration, as this would decrease the convergence time. The iterations were performed and the residuals for convergence were set to $1 \mathrm{e}-$ 6 . The following results were obtained when the solution converged.

Table -1: Boundary conditions for flow analysis

\begin{tabular}{|l|l|}
\hline Fluid & Air \\
\hline Altitude & $30000 \mathrm{ft}$ \\
\hline Mach number & 1.2 to 5 \\
\hline Pressure & $30130 \mathrm{pa}$ \\
\hline Temperature & $288 \mathrm{~K}$ \\
\hline
\end{tabular}

\section{CONTOURS \& PLOTS}

\subsection{Contours of Turbo Jet Operation at Mach} number 1.5

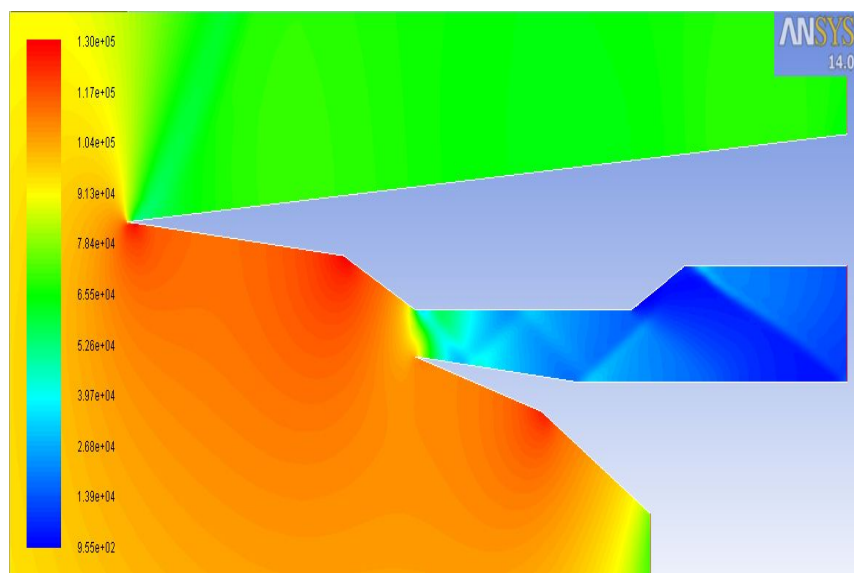

Fig -7: Pressure Contour 


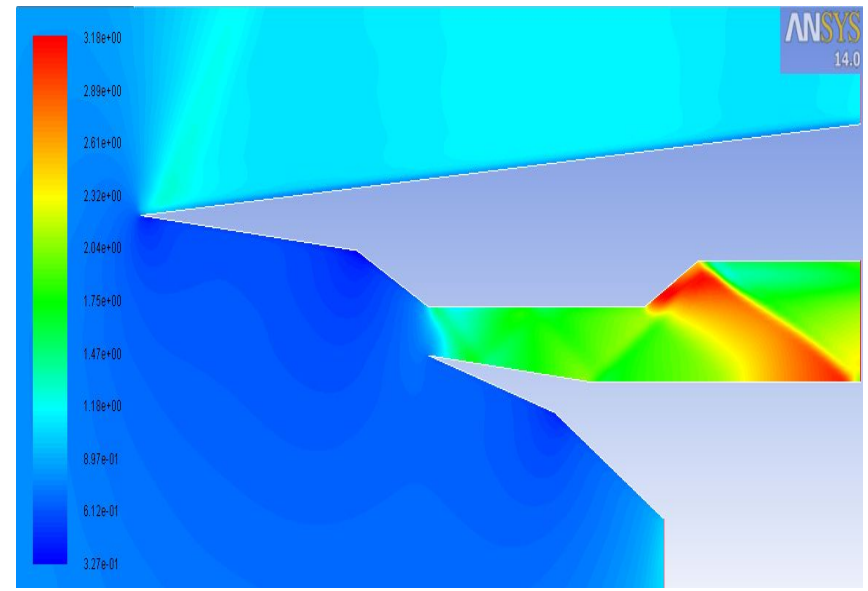

Fig -8: Velocity Contour

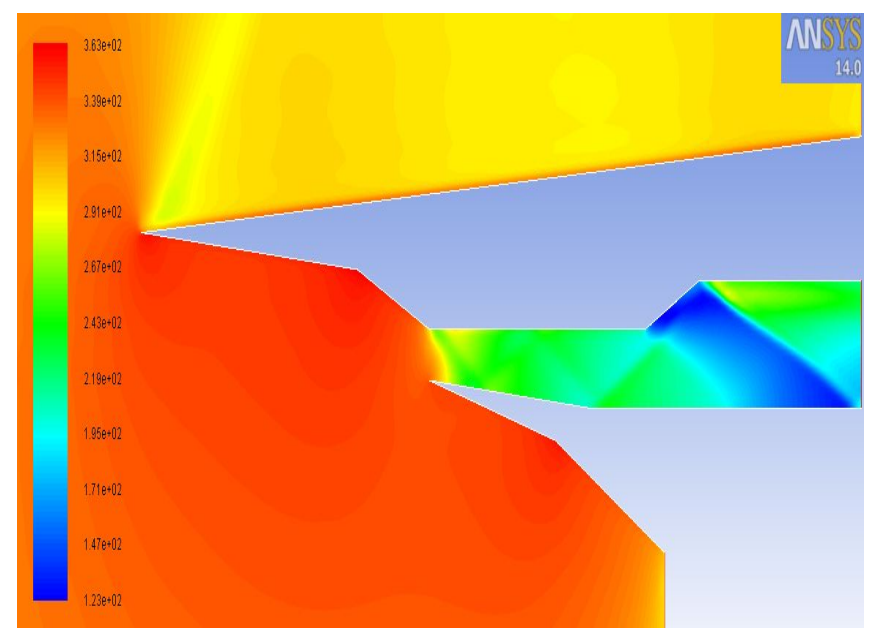

Fig -9:Temperature Contour

The interaction of shock wave is minimum and it is starting at the lower wedge part where the total pressure increases and velocity decreases continuously.

\subsection{Contours of Dual Ramjet Operation at Mach} number 2.5

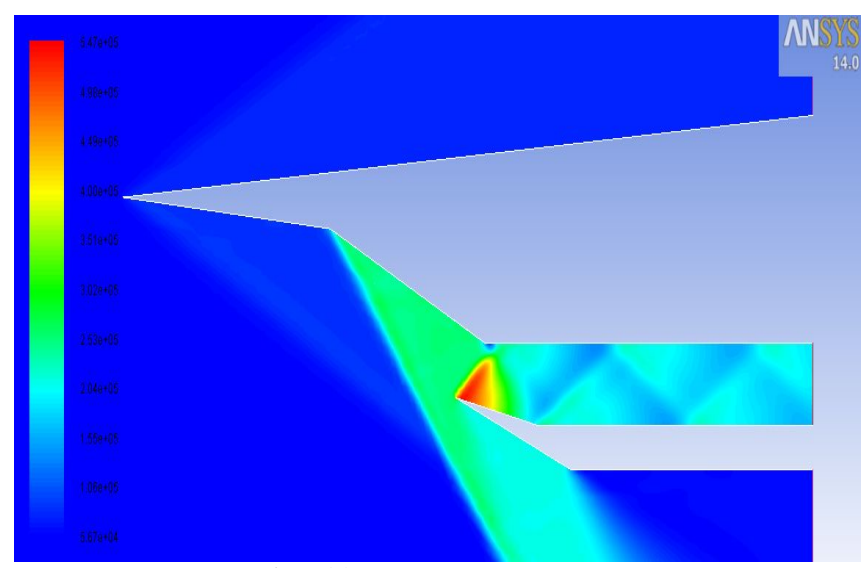

Fig -10: Pressure Contour

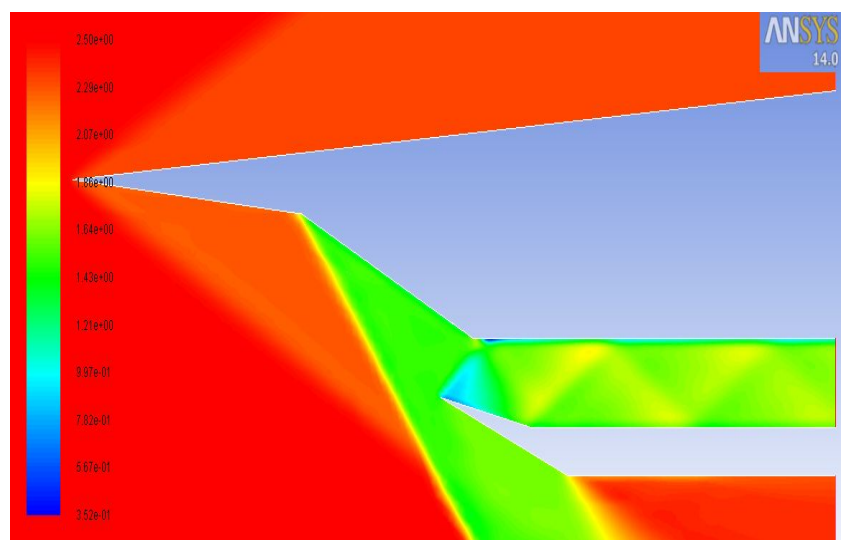

Fig -11: Velocity Contour

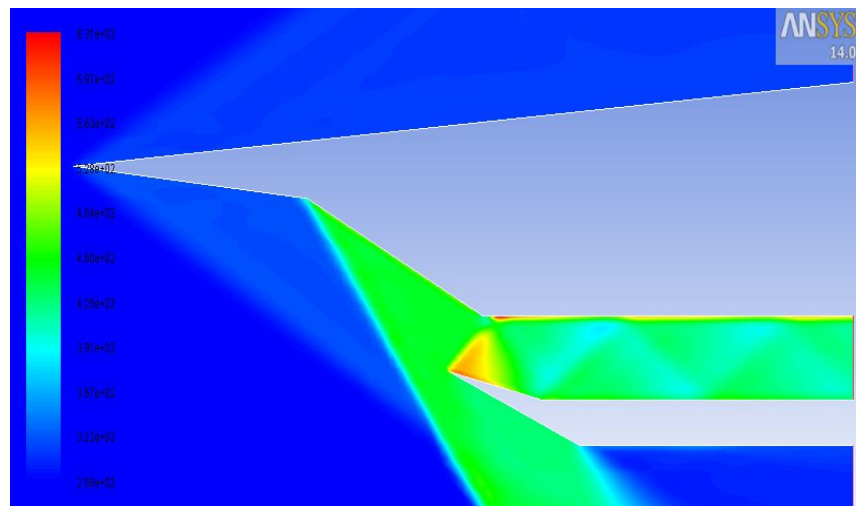

Fig -12: Temperature Contour

It was noted that the inlet of the scramjet engine was set to a linear operation of Mach number 2.5 with increase in total pressure and decrease in Mach number of the flow for supersonic combustion.

The numerical simulation was repeated for three different Mach Numbers 3, 4 and 5.

\section{THEORETICAL APPROACH FOR MACH}

\section{NUMBER 1.5}

\section{Zone1 to zone 2:}

$\begin{array}{lcl}\mathrm{M} \infty=1.5 & \mathrm{P}=30130 \mathrm{~N} / \mathrm{m} 2 & \mathrm{P} 01=10132 \\ \mathrm{M} 1=1.5 & \theta=70 & \beta=50.88\end{array}$

$\mathrm{Mn} 1=1.5 \sin (50.88)$

$\mathrm{M} 2=\mathrm{Mn} 2 / \sin (\beta-\theta)=0.8682 /(\sin (50.88-7))=1.2525$

Zone2 to Zone 3:

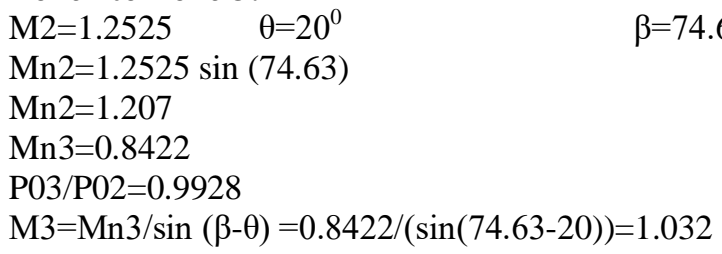

Zone 3 to Zone 4:

$\begin{array}{lrl}\text { M3 }=1.032 \quad \theta=7^{0} & & \beta=89.66 \\ M n 3=1.032 \sin (89.66) & & \\ M n 4=0.9712 & P 04 / p 03=1 & \end{array}$


$\mathrm{M} 4=\mathrm{Mn} 4 / \sin (\beta-\theta)=0.9712 /(\sin (89.66-7))=0.9782$

Zone4 to Zone 5:

M4=0.9782 $\quad \beta=89.66-15=74.66 \quad \theta=15^{0}$

$\mathrm{Mn} 4=0.9782 \sin (74.66)$

Mn5=0.9433

Final Mach number: 0.9433

$\mathrm{P} 05 / \mathrm{p} 04=\{1+2 \gamma /(\gamma+1)(\mathrm{m} 2-1)\}(-1) /(\gamma-1)\{(\gamma+1) \mathrm{m} 2 /((\gamma-$ 1)m $2+2)\} \gamma /(\gamma-1)$

$\mathrm{P} 05 / \mathrm{p} 04=\{1+1.166(-0.110)\}-2.5\{2.135 / 2.355\} 3.5$

$\mathrm{P} 05 / \mathrm{p} 04=0.5246$

$\mathrm{P} 05 / \mathrm{p} 01=\mathrm{P} 05 / \mathrm{p} 04 \times \mathrm{P} 04 / \mathrm{p} 03 \times \mathrm{P} 03 / \mathrm{p} 02 \times \mathrm{P} 02 / \mathrm{p} 01$

From the above data we obtain:

$\mathrm{P} 05 / \mathrm{p} 01=0.5191$

\section{RESULTS AND DISCUSSIONS}

The results obtained for various Mach Numbers are analysed and confirmed that the pressure recovery factor for the intake is increasing for the operation of ramjet. The pressure recovery factor for the intake performing for various Mach numbers are listed as follows.

Table -2: Boundary conditions for flow analysis

\begin{tabular}{|l|l|l|l|}
\hline $\begin{array}{l}\text { Sl. } \\
\text { No. }\end{array}$ & $\begin{array}{l}\text { M1 at various cases } \\
\text { of analysis }\end{array}$ & $\begin{array}{l}\text { Pressure } \\
\text { recovery }\end{array}$ & M2 at exit \\
\hline 1 & 1.2 & 0.1337 & 0.085 \\
\hline 2 & 1.5 & 0.3496 & 0.3897 \\
\hline 3 & 2.2 & 0.5263 & 1.0526 \\
\hline 4 & 2.5 & 3.4753 & 1.21 \\
\hline 5 & 3 & 5.6879 & 1.92 \\
\hline 6 & 4 & 18.0696 & 2.23 \\
\hline 7 & 5 & 44.8889 & 2.515 \\
\hline
\end{tabular}

From the table it is seen that the pressure recovery factor for supersonic speeds are increasing from 1.2 to 5 and the Mach number at the exit of the intake is increased for Mach number 1.2 and 1.5 and it again decreases for 2.2 because of viscous boundary layer interaction (shock interaction/reflection of shocks). Again from Mach number 2.2 to 5 the viscous boundary layer interaction increases to certain extent and increases the Mach number of the exit intake about 2.5 for $\mathrm{M}=5$.

Thus the supersonic combustion would takes place at the scramjet engine where the viscous interaction is more in high altitudes. Thus the performance of the turbo ramjet engine was studied and the effect of various Mach number and its boundary interaction where studied in various operating cases. Even then the Nozzle throat was adjusted the Mach number is further increased as well for hypersonic jets this turbo scramjet engine was the successful case for operating in supersonic combustion.

\section{CONCLUSIONS}

The performance of turbo ramjet engine intake exhibits maximum pressure recovery factor and improved deceleration ratio in turn produces the supersonic flow in the combustion chamber with increase in Mach number with optimum operating pressure. The flow properties and its behaviour of supersonic inlet performs shock interaction is studied and optimized at various operating conditions. The future scope of this work is to establish this fifth generation turbo ramjet engine in real flight conditions. The turbojet engine operating time is upto the intake Mach number of 1.5 and after that the ramjet engine operates will be concluded for our project.

\section{REFERENCES}

[1] An Integration of the Turbojet and Single-Throat Ramjet by C.J. Trefny and T.J. Benson -Lewis Research Centre Cleveland, Ohio [National aeronautics and space administration]

[2] Performance Analysis of Variable-Geometry Scramjet Inlets Using a Low-Order Model by Derek J. Dalle, Sean M. Torrez, and James F. Driscoll - University of Michigan [AIAA]

[3] Internal Aerodynamics of a Generic ThreeDimensional Scramjet Inlet at Mach 10 by Scott D. Holland - Langley Research Centre, Hampton, Virginia [National aeronautics and space administration]

[4] Shock tunnel studies on cowl/ramp shock interactions in a generic scramjet inlet Mahapatra and G Jagadeesh - Department of Aerospace Engineering, Indian Institute of Science, Bangalore, India

[5] Computational Analysis of Scramjet Inlet by $\mathrm{V}$. Rajashree, P. Manivannan, and G. Dinesh kumar published in International Journal of Innovative Research in Science, Engineering and Technology.

[6] Design of Three-Dimensional Hypersonic Inlets with Rectangular-to-Elliptical Shape Transition by M. K. Smart, NASA Langley Research Center, Hampton, Virginia

[7] Hypersonic Intake Starting Characteristics-A CFD Validation Study by SoumyajitSaha and DebasisChakraborty, Defence Research \& Development Laboratory, Hyderabad.

[8] Mach 4 Performance of Hypersonic Inlet with Rectangular-to-Elliptical Shape Transition by MK Smart, NASA Langley Research Center, Hampton, Virginia.

[9] Design and Analysis Tool for External-Compression Supersonic Inlets by John W. Slater, NASA John H. Glenn Research Center, Cleveland, Ohio

[10] Design and Analysis on Scramjet Engine Inlet by AqheelMurtuza Siddiqui1, G.M.Sayeed Ahmed, MuffakhamJah College of Engineering \& Technology., Hyderabad 


\section{BIOGRAPHIES}

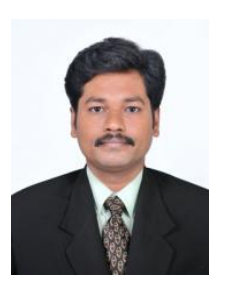

Mr. G. Madhan Kumar, B.E.(Aero), M.E.(Aero), Assistant Professor, Aerodynamics, Department of Aeronautical Engineering, SNS College of Technology, Coimbatore, TN.

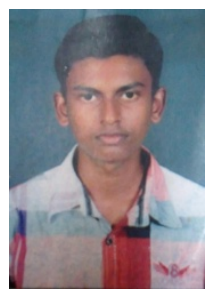

Mr. S. Sam Vimal Kumar, Pursuing B.E.(Aero), Department of Aeronautical Engineering, SNS College of technology, Coimbatore, TN.

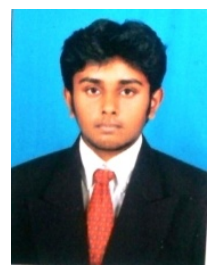

Mr. S. Z. Syed Afsar, Pursuing B.E.(Aero), Department of Aeronautical Engineering, SNS College of Technology, Coimbatore, TN.

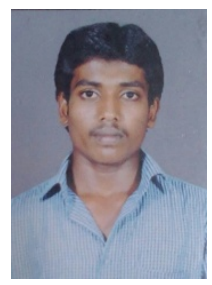

Mr. R. Selvamani, Pursuing B.E.(Aero), Department of Aeronautical Engineering, SNS College of Technology, Coimbatore. 